\title{
Endoscopic vs. conventional thyroidectomy for the treatment of benign thyroid tumors: A retrospective study of a 4-year experience
}

\author{
FEILIN CAO, BOJIAN XIE, BINBIN CUI and DONG XU \\ Department of Surgical Oncology, Taizhou Hospital, Wenzhou Medical College, Taizhou, Zhejiang 317000, P.R. China
}

Received March 11, 2011; Accepted May 9, 2011

DOI: $10.3892 /$ etm.2011.267

\begin{abstract}
Endoscopic thyroidectomy (ET) allows surgeons to remove a thyroid tumor from a remote site, while providing excellent results from a cosmetic viewpoint. The aim of this study was to explore the appropriateness and outcomes of ET via breast approach for the treatment of benign thyroid tumors. A total of 637 patients with benign thyroid tumors were recruited in our department. Two hundred and eighty-five patients underwent the ET via breast approach (ET group) and 352 matched control patients underwent conventional thyroidectomy (ConT group). Variables, such as surgery-related outcomes and postoperative complications, were compared between these two groups. A unilateral lobectomy was performed in 126 patients $(44.2 \%)$ of the ET group and in 163 patients $(46.3 \%)$ of the ConT group. A bilateral total thyroidectomy was performed in 159 patients (55.8\%) of the ET group and in 189 patients $(53.7 \%)$ of the ConT group. The operative time in the ET group was longer compared to the ConT group $(79.9 \pm 20.10$ vs. $45.4 \pm 11.90 \mathrm{~min}, \mathrm{P}<0.001$, for unilateral lobectomy; and $89.9 \pm 14.60$ vs. $60.0 \pm 8.44 \mathrm{~min}$, $\mathrm{P}<0.001$, for bilateral total thyroidectomy). The ET group had a significantly longer mean hospital stay compared to the ConT group $(5.5 \pm 0.50$ vs. $5.3 \pm 0.75$ days, $\mathrm{P}=0.002)$. There was no case of conversion to conventional open surgery in the ET group. The recurrent laryngeal nerves and parathyroid glands were identified and protected in all cases. Our results indicate that ET performed via breast is a technically feasible and safe procedure with excellent cosmetic results for patients with benign thyroid tumors.
\end{abstract}

\section{Introduction}

The frequency of benign and malignant thyroid tumors has experienced a significant rise in the last 20 years in the

Correspondence to: Dr Feilin Cao, Department of Surgical Oncology, Taizhou Hospital, Wenzhou Medical College, 150 Ximen Road, Taizhou, Zhejiang 317000, P.R. China

E-mail:dr.caofeilin@yahoo.com.cn

Key words: benign thyroid tumor, cosmetic, endoscopic, thyroidectomy
Mainland of China, partially due to an increase in public awareness, utilization of diagnostic tools and routine physical examinations. Conventional thyroidectomy (ConT) through a skin-crease incision in the anterior neck has been the proven, efficacious surgical method for treating various thyroid tumors for the past few decades. ConT requires a cervical collar incision, leaving an unsightly scar. However, numerous patients with thyroid tumors who require operation are young women and they are often concerned about the cosmetic appearance of the scar. Consequently, the demand for surgical procedures which avoid visible scars while maintaining optimal functional and ideal cosmetic results is increasing.

The goals of endoscopic thyroidectomy (ET) are to limit external scarring and improve cosmesis, to reduce postoperative pain, to enhance postoperative recovery and to achieve these ends without compromising treatment efficacy. ET was first described by Hüscher et al (1) in 1997. Most of the earlier endoscopic approaches to the thyroid gland employed small cervical incisions in the midline or laterally. To avoid a visible scar in the neck, non-cervical approaches to the thyroid gland have been employed. The most commonly used non-cervical approaches are the axillary (2), the breast (3), the lateral (4) and also certain hybrid approaches (5), such as the axillarybilateral breast approach, the bilateral axillo-breast approach, the unilateral axillo-breast approach, and the postauricular and axillary approach. Among these, the breast approach has emerged as the clear favorite as evidenced by its exponential growth in number in the Mainland of China (6).

It may be due to the Chinese culture that avoidance of a cervical neck scar justifies the expense of technological investment combined with a lengthy procedure to approach the thyroid compartment remotely, which has promoted the widespread application of ET in the Mainland of China (6). The preponderance of females among patients requiring thyroid surgery has probably been another influence in the development and patient acceptance of ET. In our department, ET via breast approach was developed in 2007 and, since then, approximately 300 operations have been performed. The aim of this retrospective study was to compare the surgical results of patients who underwent ET and to those of patients who underwent ConT. Herein, we summarize the results of the ET and demonstrate its feasibility and safety via breast approach for the treatment of benign thyroid tumors. 


\section{Materials and methods}

Patients. From January 2007 to December 2010, 285 patients were treated with ET via breast approach. All were concerned with the cosmetic appearance of the neck and chose this procedure as the preferred surgical treatment. Another group of 352 patients treated with ConT during the same period in our department served as matched controls. The characteristics of the patients are shown in Table I. This was a retrospective analysis of the surgical outcomes for two types of thyroidectomy (ET and ConT), performed by the same group of surgeons. All operations in both groups were performed by a single surgeon (F. Cao) assisted by two of the authors (B. Xie and B. Cui). All cases were identified from a thyroid surgery patient database, prospectively maintained by one of the authors (D. Xu). Informed consent was obtained from each patient before surgery in all cases. The study was approved by the Institutional Review Board of our hospital.

All patients were evaluated pre-operatively using ultrasonography, computed tomographic scan and fine-needle aspiration cytology. All patients underwent pre-operative direct laryngoscopy to assess vocal cord motility. The inclusion criteria used for ET are shown in Table II. The ConT group was chosen with the same inclusion criteria used for ET. The main surgical outcome measures were operative time (the interval from the skin incision to closure of the skin), postoperative hospital stay, identification of recurrent laryngeal nerves (RLN), identification of parathyroid glands, conversion to an open surgical procedure, postoperative calcemia, postoperative vocal alteration, postoperative complications and the pathological characteristics. The following complications were analyzed: transient or permanent RLN palsy, transient or permanent hypocalcemia, reoperation for hemorrhage and postoperative pain. Patients were tested for hypocalcemia preoperatively and on postoperative days 1 and 30. All patients with postoperative calcium level below the lower limit of the normal range $(8.2-10.6 \mathrm{mg} / \mathrm{dl})$ were considered as having hypocalcemia. In this study, hypocalcemia and RLN palsy were defined as permanent when there was no evidence of recovery within 30 days after surgery. The patients in both groups were followed up at days 7 and 30 through office visits or phone calls. Follow-up examination included hoarse voice, swallowing difficulty, hypesthesia or paresthesia and cosmetic satisfaction. The patients were asked to grade the cosmetic appearance of their wound 1 month after surgery. All patients were provided with four ratings of cosmetic satisfaction: poor, acceptable, good and excellent. The data were analyzed for statistical significance using a Student's t-test and Chi-square test; p-values $<0.05$ were considered significant.

\section{Surgical procedure}

ET procedure. Under general anesthesia and endotracheal intubation, ET via breast approach was performed. Patients were placed in the supine position with extension of the neck. A $15-\mathrm{mm}$ incision in the presternal region (for placement of the Hanson trocar), and two 5-mm incisions in the superior areas of both mammary areolas were selected (Fig. 1). A dilute epinephrine saline solution $(1: 200,000)$ was injected into the subcutaneous space in the breast and subplatysmal space in the neck to ease flap dissection and to prevent bleeding.
Table I. Clinical data and surgical outcomes of the patients.

\begin{tabular}{|c|c|c|c|}
\hline & $\begin{array}{c}\text { ET } \\
(n=285)\end{array}$ & $\begin{array}{c}\text { ConT } \\
(n=352)\end{array}$ & P-value \\
\hline Age (years) & & & $<0.001$ \\
\hline Mean (SD) & 35.7 (12.59) & $40.0(11.14)$ & \\
\hline Range & $17-55$ & $22-68$ & \\
\hline \multicolumn{4}{|l|}{ Gender } \\
\hline Male (n/\%) & $10 / 3.5$ & $42 / 11.9$ & \\
\hline Female (n/\%) & $275 / 96.5$ & $310 / 88.1$ & \\
\hline \multicolumn{4}{|l|}{ Operative methods } \\
\hline $\begin{array}{l}\text { Unilateral } \\
\text { lobectomy (n/\%) }\end{array}$ & $126 / 44.2$ & $163 / 46.3$ & \\
\hline $\begin{array}{l}\text { Bilateral total } \\
\text { thyroidectomy }(\mathrm{n} / \%)\end{array}$ & $159 / 55.8$ & $189 / 53.7$ & \\
\hline \multicolumn{4}{|l|}{ Operative time (min) } \\
\hline $\begin{array}{l}\text { Unilateral lobectomy } \\
\text { (mean/SD) }\end{array}$ & $79.9 / 20.10$ & $45.4 / 11.90$ & $<0.001$ \\
\hline $\begin{array}{l}\text { Bilateral total } \\
\text { thyroidectomy } \\
\text { (mean/SD) }\end{array}$ & $89.9 / 14.60$ & $60.0 / 8.44$ & $<0.001$ \\
\hline $\begin{array}{l}\text { Postoperative hospital } \\
\text { stay (days, mean /SD) }\end{array}$ & $5.5 / 0.50$ & $5.3 / 0.75$ & 0.002 \\
\hline $\begin{array}{l}\text { Conversion to open } \\
\text { surgical procedure }\end{array}$ & None & None & \\
\hline RLN identification & All & All & \\
\hline PG identification & All & All & \\
\hline
\end{tabular}

ET, endoscopic thyroidectomy group; ConT, conventional thyroidectomy group; RLN, recurrent laryngeal nerves; PG, parathyroid glands.

Table II. Inclusion criteria.

No suspicion of malignancy

A fine-needle aspiration cytology report of a

benign thyroid lesion

Thyroid goiter or nodules $<5 \mathrm{~cm}$ in diameter

Thyroid gland volume $<25 \mathrm{ml}$

No history of thyroiditis

No history of hyperthyroidism

No previous neck surgery

No irradiation

Using a vascular tunneler (GORE Tunneler-Standard Curve Access; W.L. Gore \& Associates, Inc., Flagstaff, AZ, USA), the working space was extended. After blunt dissection of the subcutaneous tissue of the anterior chest wall through this incision, a $15-\mathrm{mm}$ trocar was inserted. The working area was maintained with low pressure $\mathrm{CO}_{2}$ insufflation at a pressure of $6 \mathrm{mmHg}$, and a 30-degree 5-mm flexible endoscope (Olympus, Tokyo, Japan) was inserted through the trocar. The working space was made widely to the level of the thyroid cartilage cranially and to the medial edge of each of the 


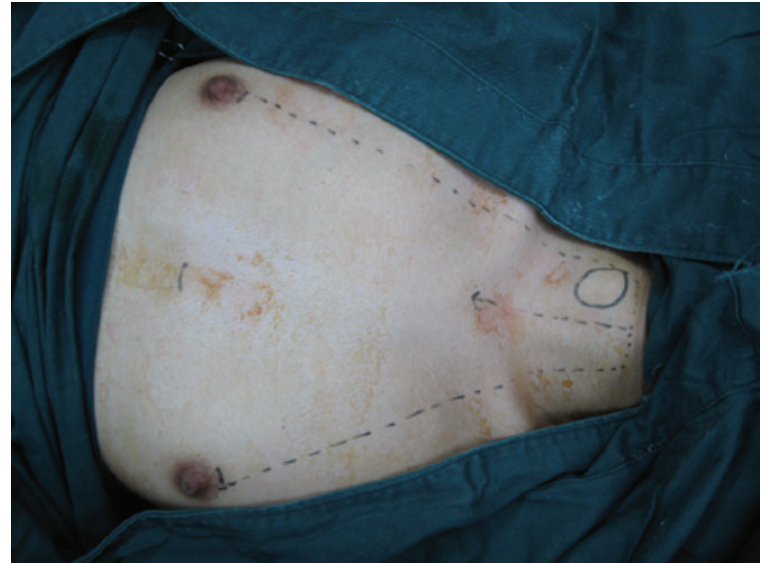

Figure 1. Surface marking.

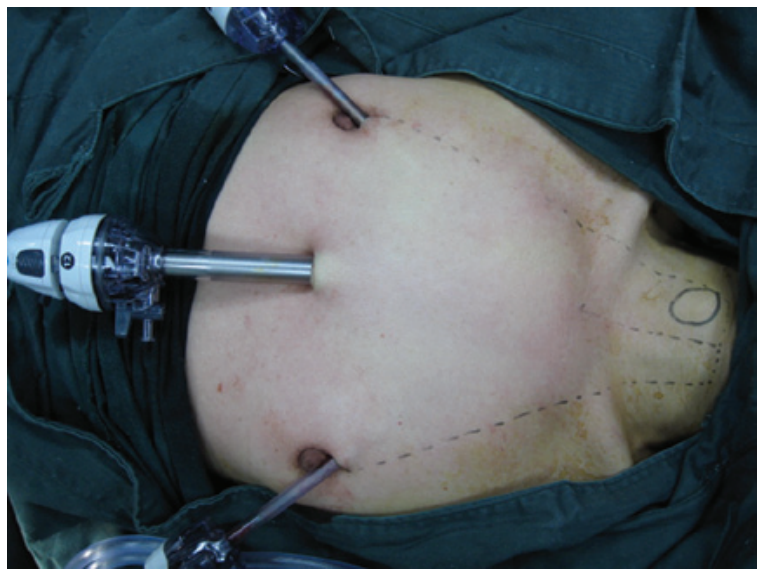

Figure 2. Incisions were made and trocars were inserted.

sternocleidomastoid muscles laterally with the visual guidance of the endoscope. After the working space was set up, two 5-mm incisions were made and two 5-mm trocars were inserted (Fig. 2). Thyroid vessel management and thyroidectomy were performed endoscopically using a 5-mm ultrasonic coagulation device (Harmonic Scalpel; Ethicon Endosurgery, USA). After dissecting the strap muscles in the midline endoscopically, the isthmus was divided. Traction over the ipsilateral strap muscles was then oriented laterally to reveal the right lobe. After cutting the inferior thyroid arteries and veins and the middle thyroid vein, the lobe was retracted downward to expose the superior thyroid arteries, which were then dissected by the Harmonic Scalpel. After that, the lobe was gently lifted up and the whole cervical course of the RLN up to the inferior constrictor of the pharynx was traced and protected, as well as both the inferior and superior parathyroid glands. The magnification of the endoscope allowed easy identification of the RLN and the parathyroid glands (Figs. 3 and 4). Lastly, the lobe was excised from the inferior pole up towards the superior pole. The left lobe was excised in the same manner to the right lobe. The resected specimen was inserted into a retrieval bag and retrieved through the $15-\mathrm{mm}$ port. A frozen section of the resected specimen was examined intraoperatively for pathological confirmation. Homeostasis was checked at the end of dissection. After

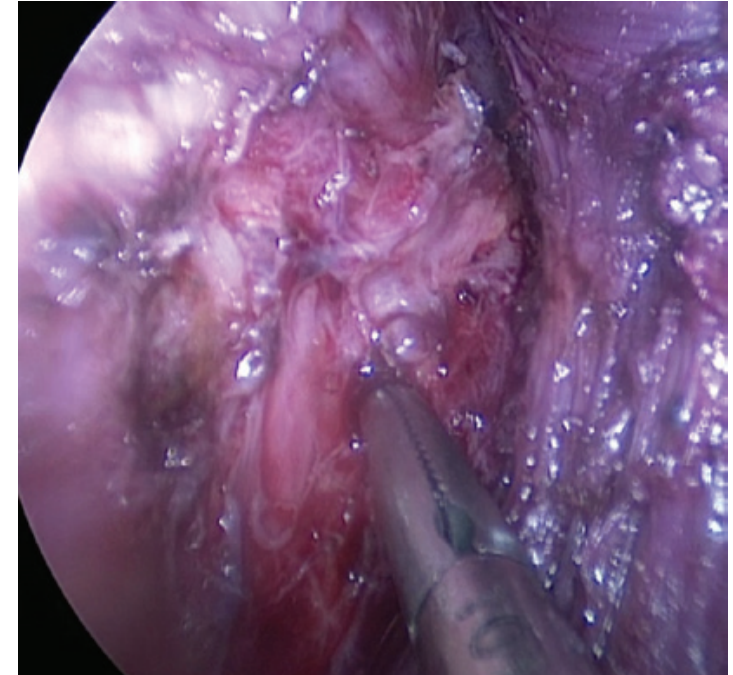

Figure 3. Parathyroid gland was identified easily with the lateral view of the thyroid gland and the paratracheal region.

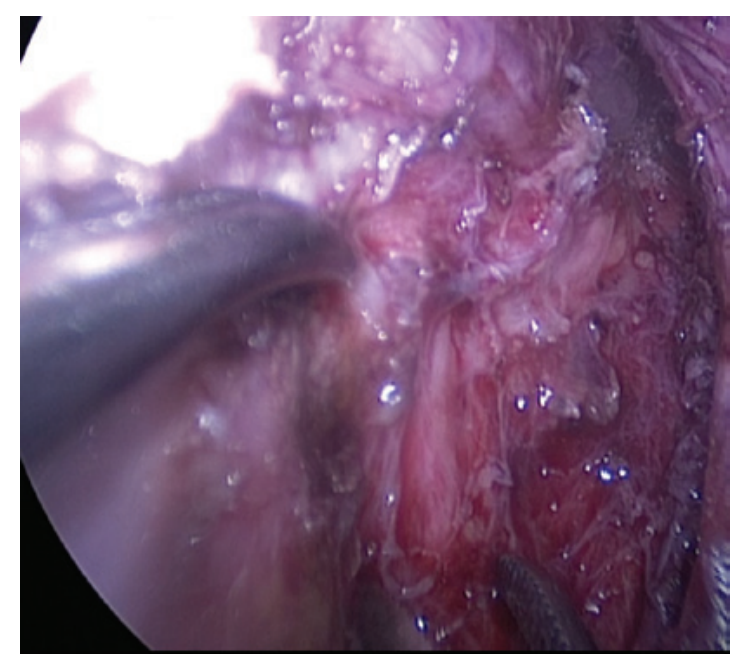

Figure 4. Recurrent laryngeal nerve was identified easily with the lateral view of the thyroid gland and the paratracheal region.

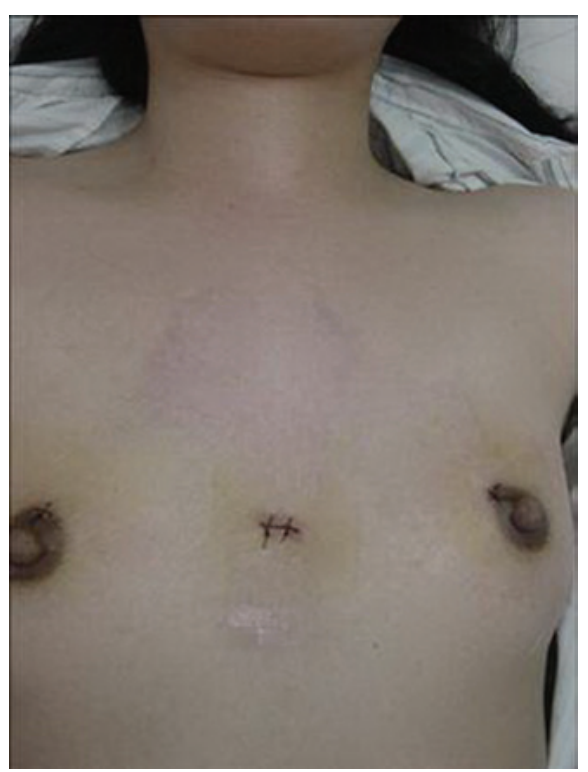

Figure 5. Cosmetic effect after endoscopic thyroidectomy. 
cleaning the cavity with physiological saline solution, the strap muscles were sutured. An aspiration drainage tube was left in situ in the central compartment, and it was removed $48 \mathrm{~h}$ after surgery (Fig. 5).

ConT procedure. Under general anesthesia, the patient was placed in a supine position and the neck was extended. A 5- to 8-cm transverse collar skin incision was made in the mid-line of the anterior neck $2 \mathrm{~cm}$ above the sternal notch, and the lower layer of the platysma was exposed under direct vision. Subplatysmal flap dissection was performed to achieve adequate working space from the sternal notch to the hyoid bone level superiorly, and both the medial side of the anterior border of the sternocleidomastoid muscle laterally. The midline of the strap muscles was divided vertically and the thyroid gland was exposed. A bilateral total thyroidectomy or unilateral lobectomy was performed manually in the same manner as the endoscopic procedure. Before concluding the operation, a 3-mm closed suction drain was placed through the separate skin incision. The wounds were closed with absorbable suture material by a continuous subcutis suture method.

\section{Results}

Two hundred and eighty-five patients underwent ET via breast approach (ET group), and 352 patients underwent ConT (ConT group). The mean ages of the patients were $35.7 \pm 12.59$ years (range 17-55) in the ET group and 40.0 \pm 11.14 years (range 22-68) in the ConT group $(\mathrm{P}<0.001)$. The male-to-female gender ratios were 10:275 (1:27.5) in the ET group and 42:310 $(1: 7.38)$ in the ConT group $(\mathrm{P}<0.001)$. A unilateral lobectomy was performed in 126 patients (44.2\%) of the ET group and in 163 patients (46.3\%) of the ConT group. A bilateral total thyroidectomy was performed in 159 patients $(55.8 \%)$ of the ET group and in 189 patients $(53.7 \%)$ of the ConT group. Patient characteristics are presented in Table I.

The total operative time for the ET group was significantly longer compared to the ConT group $(79.9 \pm 20.10$ vs. $45.4 \pm 11.90 \mathrm{~min}, \mathrm{P}<0.001$, for unilateral lobectomy; and $89.9 \pm 14.60$ vs. $60.0 \pm 8.44 \mathrm{~min}, \mathrm{P}<0.001$, for bilateral total thyroidectomy) (Table I). The length of postoperative hospital stay of the ET group was significantly longer compared to that of the ConT group $(5.5 \pm 0.50$ vs. $5.3 \pm 0.75$ days, $\mathrm{P}=0.002)$. There was no case of conversion to the conventional open surgery in the ET group. RLN and parathyroid glands were identified in all cases (Table I).

An endoscopic approach provides better, magnified views of the RLN and the parathyroid glands resulting in fewer complications. The postoperative complications of both groups are shown in Table III. Transient hypocalcemia was found in 1.4\% (4/285) of the ET group and 4.3\% (15/352) of the ConT group cases. No permanent hypocalcemia occurred in the ET group, but one occurred in the ConT group. Transient RLN palsy occurred in $3.2 \%(9 / 285)$ of the ET group and $3.7 \%$ (13/352) of the ConT group. No permanent RLN palsy occurred in each group. Postoperative pain in the ET and ConT groups occurred in 4.6\% (13/285) and 4.3\% (15/352), respectively, at $24 \mathrm{~h}$ after operation.

To evaluate the cosmetic results, a simple questionnaire was used (Table IV). Among the 282 responses in the ET group,
Table III. Postoperative complications.

\begin{tabular}{lccc}
\hline & $\begin{array}{c}\text { ET } \\
(\mathrm{n}=285)\end{array}$ & $\begin{array}{c}\text { ConT } \\
(\mathrm{n}=352)\end{array}$ & \\
\hline Postoperative complications & $\mathrm{n}(\%)$ & $\mathrm{n}(\%)$ & P-value \\
\hline Transient RLN palsy & $9(3.2)$ & $13(3.7)$ & 0.713 \\
Permanent RLN palsy & 0 & 0 & \\
Transient hypocalcemia & $4(1.4)$ & $15(4.3)$ & 0.035 \\
Permanent hypocalcemia & 0 & $1(0.3)$ & 0.368 \\
Reoperation for hemorrhage & 0 & 0 & \\
Postoperative pain & $13(4.6)$ & $15(4.3)$ & 0.854 \\
Hoarse voice & $5(1.8)$ & $6(1.7)$ & 0.962 \\
Swallowing difficulty & 0 & 0 & \\
Hypesthesia or paresthesia & $1(0.4)$ & $2(0.6)$ & 0.690 \\
\hline
\end{tabular}

ET, endoscopic thyroidectomy group; ConT, conventional thyroidectomy group; RLN, recurrent laryngeal nerves.

Table IV. Patient satisfaction with cosmetic results.

\begin{tabular}{lccr}
\hline & ET $(\mathrm{n}=282)$ & ConT $(\mathrm{n}=352)$ & \\
\hline Cosmetic effects & $\mathrm{n}(\%)$ & $\mathrm{n}(\%)$ & P-value \\
\hline Excellent & $222(78.7)$ & $26(7.4)$ & $<0.001$ \\
Good & $39(13.9)$ & $181(51.4)$ & $<0.001$ \\
Acceptable & $21(7.4)$ & $132(37.5)$ & $<0.001$ \\
Poor & 0 & $13(3.7)$ & 0.001 \\
\hline
\end{tabular}

ET, endoscopic thyroidectomy group; ConT, conventional thyroidectomy group.

Table V. Histopathological findings.

\begin{tabular}{lcc}
\hline & ET $(\mathrm{n}=285)$ & ConT $(\mathrm{n}=352)$ \\
\hline Histopathology & $\mathrm{n}(\%)$ & $\mathrm{n}(\%)$ \\
\hline Nodular goiter & $221(77.5)$ & $256(72.7)$ \\
Adenoma & & \\
Follicular adenoma & $41(14.4)$ & $57(16.2)$ \\
Hurthle cell adenoma & $20(7.0)$ & $39(11.1)$ \\
Cystic lesions & $3(1.1)$ & 0 \\
\hline
\end{tabular}

ET, endoscopic thyroidectomy group; ConT, conventional thyroidectomy group.

$78.7 \%$ (222/282) were 'Excellent', 13.9\% (39/282) were 'Good', $7.4 \%$ (21/282) were 'Acceptable' and there were no 'Poor' responses. Among the 352 responses in the ConT group, 7.4\% (26/352) were 'Excellent', 51.4\% (181/352) were 'Good', 37.5\% (132/352) were 'Acceptable' and 3.7\% (13/352) were 'Poor'. Patients in the ET group had statistically significantly better 
cosmetic results compared to the ConT group (Table IV). No tracheal and esophageal injury occurred in each group.

Two hundred and twenty-one patients $(77.5 \%)$ in the ET group and 256 patients $(72.7 \%)$ in the ConT group had nodular goiter on histopathological examination (Table V). Forty-one patients $(14.4 \%)$ in the ET group and 57 patients (16.2\%) in the ConT group had follicular adenoma, and 20 patients $(7.0 \%)$ in the ET group and 39 patients $(11.1 \%)$ in the ConT group had Hurthle cell adenoma. Only 3 patients $(1.1 \%)$ in the ET group had cystic lesions (Table V).

\section{Discussion}

A new surgical technique when developed has to face up to its conventional standard and be comparable when it comes to results achieved, complications, safety, technical feasibility and cost-to-benefit ratio. A considerable recent surge has occurred in the development of endoscopic techniques in thyroid surgery. Since Gagner (7) and Hüscher et al (1) first reported successful endoscopic neck surgery in 1996 and 1997, several endoscopic thyroid surgical techniques have been developed (8-14). Minimizing surgical stress, cosmetic concerns and improving the postoperative quality of life are the main motivations for developing novel endoscopic thyroid surgical techniques. According to the insertion site of surgical instruments, endoscopic surgery can be classified as cervical $(15,16)$, anterior chest wall (10), breast (17), axillary (18-20) and axillary breast approaches (21). These various techniques of endoscopic thyroidectomy have their own advantages and pitfalls. There were five published series involving 169 patients of ET performed via breast approach (17). We carried out this clinical observation after conducting 285 cases with ET via breast approach to provide an adequate match with our experience in conventional open surgery.

The mean operative time of ET in our series was $79.9 \pm 20.10 \mathrm{~min}$ for unilateral lobectomy and 89.9 $\pm 14.60 \mathrm{~min}$ for bilateral total thyroidectomy (Table I). The acceptable operative time achieved was due to the short learning curve, the good surgical view, magnification of the surgical field, excellent instrumentation and the breast approach to the thyroid gland. Operative time is the only factor in our series that did not compare favorably to the open surgical procedure. However, the longer operative time compared to the open surgery group could be possibly reduced further through the accumulation of experience.

Although the conversion rates of ET via breast approach are reported to be $0-13 \%$ (22-24), we did not have any conversions. This directly relates to the prior endoscopic experience of the main surgeon in endoscopic thyroid surgery with formal training as well as his own experience with previous open thyroid lobectomies. As is the case with open surgery, exposure to a high volume of cases enables one to be comfortable with the surgical anatomy.

The common complications of endoscopic thyroidectomy were transient/permanent hypocalcemia and transient/permanent RLN palsy. With the lateral view of the thyroid gland and the paratracheal region, we easily identified and preserved the RLN and parathyroid glands while performing the ET. In the present study, the superior parathyroid gland was often easier to identify and dissect from the thyroid gland on a vascular pedicle than in open thyroidectomy. We experienced a lower incidence of transient hypocalcemia in the ET group than previous reports (22-24) (Table III). All patients with transient hypocalcemia recovered within 1 month. Several patients who underwent our endoscopic thyroid surgery reported mild hypesthesia and paresthesia in the neck and anterior chest wall. In addition, some of the patients reported discomfort while swallowing (Table III). Therefore, the invasiveness of significant dissection to achieve an adequate working space should be improved through the accumulation of experience.

Cosmetic results are difficult to evaluate because of the reliance on the subjective judgment of the patient. However, most of the patients in the ET group were satisfied with the operative scars (Table IV), and 222 patients (78.7\%) were extremely satisfied with their cosmetic results.

ET via breast approach was not pioneered by Chinese endoscopic surgeons, but we did contribute towards improvement in technical details. Firstly, prior injection of $300 \mathrm{ml}$ of diluted epinephrine saline solution into the subcutaneous space by a long needle (modified from a Veress needle) along the prospective operative tunnel up to the sternal notch greatly facilitates the creation of an adequate working space, which results in better pain and bleeding control. Secondly, low-pressure $\mathrm{CO}_{2}(6 \mathrm{mmHg})$ was applied and was still able to obtain a satisfactory operative view. No subcutaneous emphysema occurred. Therefore, we believe that $\mathrm{CO}_{2}$ insufflation for endoscopic thyroid surgery is safe if insufflation is maintained at a low pressure. Thirdly, the Harmonic Scalpel exclusively for hemostasis was used in ET without any ties or clips, and no postoperative hemorrhage or hematoma occurred in the ET group. The advantage of this device is that it does not smoke, causes minimal tissue injury, is safe for the surgeon and patient and facilitates dissection $(22,25,26)$. Fourthly, the $30^{\circ}$ endoscope was used, as it has a larger visual field, and thus makes the best use of operating space. Lastly, some major improvements and safer technologies, such as intraoperative neuromonitoring to prevent RLN paralysis and early measurement of quick intraoperative parathyroid hormone to avert symptomatic hypocalcemia, have been proposed and would be considered for application to thyroid surgery in subsequent years.

In conclusion, ET performed via breast approach is a technically feasible and safe procedure with excellent cosmetic results for patients with benign thyroid tumors. In addition to improved cosmesis, numerous patients experience decreased pain and faster recovery, and are at no increased risk for complications.

\section{Acknowledgements}

This study was supported by the Science Research Fund of Taizhou.

\section{References}

1. Hüscher CS, Chiodini S, Napolitano C and Recher A: Endoscopic right thyroid lobectomy. Surg Endosc 11: 877, 1997.

2. Duncan TD, Rashid Q, Speights F and Ejeh I: Endoscopic transaxillary approach to the thyroid gland: our early experience. Surg Endosc 21: 2166-2171, 2007. 
3. Cho YU, Park IJ, Choi KH, Kim SJ, Choi SK, Hur YS, Lee KY, Ahn SI, Hong KC, Shin SH, Kim KR and Woo ZH: Gasless endoscopic thyroidectomy via an anterior chest wall approach using a flap-lifting system. Yonsei Med J 48: 480-487, 2007.

4. Palazzo FF, Sebag F and Henry JF: Endocrine surgical technique: endoscopic thyroidectomy via the lateral approach. Surg Endosc 20: 339-342, 2006.

5. Lee KE, Kim HY, Park WS, Choe JH, Kwon MR, Oh SK and Youn YK: Postauricular and axillary approach endoscopic neck surgery: a new technique. World J Surg 33: 767-772, 2009.

6. Ng WT: Endoscopic thyroidectomy in China. Surg Endosc 23 $1675-1677,2009$

7. Gagner M: Endoscopic subtotal parathyroidectomy in patients with primary hyperparathyroidism. Br J Surg 83: 875, 1996.

8. Miccoli P, Pinchera A, Cecchini G, Conte M, Bendinelli C, Vignali E, Picone A and Marcocci C: Minimally invasive, videoassisted parathyroid surgery for primary hyperparathyroidism. J Endocrinol Invest 20: 429-430, 1997.

9. Yeung GH: Endoscopic surgery of the neck: a new frontier. Surg Laparosc Endosc 8: 227-232, 1998.

10. Shimizu K, Akira S, Jasmi AY, Kitamura Y, Kitagawa W, Akasu $\mathrm{H}$ and Tanaka S: Video-assisted neck surgery: endoscopic resection of thyroid tumors with a very minimal neck wound. J Am Coll Surg 188: 697-703, 1999.

11. Bellantone R, Lombardi CP, Raffaelli M, Rubino $F$ Boscherini M and Perilli W: Minimally invasive, totally gasless video-assisted thyroid lobectomy. Am J Surg 177: 342-343, 1999

12. Yeh TS, Jan YY, Hsu BR, Chen KW and Chen MF: Videoassisted endoscopic thyroidectomy. Am J Surg 180: 82-85, 2000.

13. Ikeda Y, Takami H, Niimi M, Kan S, Sasaki Y and Takayama J. Endoscopic thyroidectomy by the axillary approach. Surg Endosc 15: 1362-1364, 2001

14. Yamashita H, Watanabe S, Koike E, Ohshima A, Uchino S, Kuroki S, Tanaka M and Noguchi S: Video-assisted thyroid lobectomy through a small wound in the submandibular area. Am J Surg 183: 286-289, 2002.

15. Miccoli P, Berti P, Bendinelli C, Conte M, Fasolini F and Martino E: Minimally invasive video-assisted surgery of the thyroid: a preliminary report. Langenbecks Arch Surg 385: $261-264,2000$
16. Gagner M and Inabnet WB III: Endoscopic thyroidectomy for solitary thyroid nodules. Thyroid 11: 161-163, 2001.

17. Tan CT, Cheah WK and Delbridge L: 'Scarless' (in the neck) endoscopic thyroidectomy (SET): an evidence-based review of published techniques. World J Surg 32: 1349-1357, 2008.

18. Ikeda Y, Takami H, Sasaki Y, Kan S and Niimi M: Endoscopic resection of thyroid tumors by the axillary approach. J Cardiovasc Surg 41: 791-792, 2000.

19. Ikeda Y, Takami H, Sasaki Y, Kan S and Niimi M: Endoscopic neck surgery by the axillary approach. J Am Coll Surg 191 336-340, 2000

20. Yoon JH, Park CH and Chung WY: Gasless endoscopic thyroidectomy via an axillary approach: experience of 30 cases. Surg Laparosc Endosc Percutan Tech 16: 226-231, 2006.

21. Chung YS, Choe JH, Kang KH, Kim SW, Chung KW, Park KS, Han W, Noh DY, Oh SK and Youn YK: Endoscopic thyroidectomy for thyroid malignancies: comparison with conventional open thyroidectomy. World J Surg 31: 2302-2306, 2007.

22. Ohgami M, Ishii S, Arisawa Y, Ohmori T, Noga K, Furukawa T and Kitajima M: Scarless endoscopic thyroidectomy: breast approach for better cosmesis. Surg Laparosc Endosc Percutan Tech 10: 1-4, 2000.

23. Park YL, Han WK and Bae WG: 100 cases of endoscopic thyroidectomy: breast approach. Surg Laparosc Endosc Percutan Tech 13: 20-25, 2003.

24. Sasaki A, Nakajima J, Ikeda K, Otsuka K, Koeda K and Wakabayashi G: Endoscopic thyroidectomy by the breast approach: a single institution's 9-year experience. World J Surg 32: 381-385, 2008

25. Amaral JF: The experimental development of an ultrasonically activated scalpel for laparoscopic use. Surg Laparosc Endosc 4: 92-99, 1994.

26. Voutilainen PE, Haapiainen RK and Haglund CH: Ultrasonically activated shears in thyroid surgery. Am J Surg 175: 491-493, 1998. 